\title{
Nager Syndrome Does Not Preclude Organ Donation
}

\author{
Subhashini Ayloo ${ }^{1}$, Jordan Nantais ${ }^{1}$, Sertac Cimen $^{1,2}$, Sanem Guler $^{1}$ and Michele Molinari ${ }^{1 *}$ \\ ${ }^{1}$ Department of Surgery, Dalhousie University, Nova Scotia, Canada \\ ${ }^{2}$ Department of Public Health, Dalhousie University, Nova Scotia, Canada
}

Received: August 09, 2014; Accepted: September 08, 2014; Published: September 22, 2014

*Corresponding author: Michele Molinari, Department of Surgery, Dalhousie University, 1276 South Park Street,Halifax, Nova Scotia, Canada, Tel : 1-902-473-7624; Fax : 1-902-473-7639; E-mail: michele.molinari@cdha.nshealth.ca

\section{Background}

Nager Syndrome is characterized by craniofacial and upper limb anomalies. The majority of patients are affected by sporadic disease. Yet, familial cases have been reported where patients are affected by mutations in SF3B4 gene or express 3p14 common fragile site. Aberrations in the first, second branchial arches and limb buds are responsible for the phenotypic presentations [1,2]. The diagnostic features of NS can be categorized into craniofacial, limb and skeletal anomalies that give these patients an atypical appearance. Hallmark of the facial findings are: down slanting palpebral fissures, malar and mandibular hypoplasia, high nasal bridge, micrognathia, external ear anomalies, and cleft palate. Upper limb deformities include thumb anomalies, radial defect and radioulnar synostosis and axial skeletal anomalies with short stature [3]. In addition, other features that have been less often identified in NS are internal organ anomalies associated with cardiovascular, gastrointestinal, genitourinary and central nervous systems [4]. To our knowledge, no previous reports of patients with Nager Syndrome (NS) and solid organ donation have been described in the literature.

\section{Case Presentation}

A 26-year-old woman presented to the local emergency department for severe headache and decreased consciousness. Reviewing her history, she was diagnosed with NS (fragile chromosome 3) at childhood. Her mental development was to the level of an adolescent (12 or 13 year old) and able to care for herself and attend school. No other members of her family carried similar diagnosis. On physical exam she had an atypical appearance. Her height, weight and body mass index were $135 \mathrm{~cm}$, $34 \mathrm{~kg}$ and 18.7 respectively, with high nasal bridge, micrognathia, loss of neck contour and internal rotation of forearms. There were no other significant external physical findings on cardiac, lung or abdominal exam. Computer Tomography of her brain showed three cerebral arterial aneurysms that were clipped but the patient continued to deteriorate and she was eventually declared brain dead. Her family consented for multi-organ donation.

\section{Investigations}

Prior to her donation, chest radiogram, serum renal function tests, transaminases, total bilirubin, coagulation profile, arterial blood gas and glucose levels were all within the normal limits.
Several transplant centers were contacted and the patient was considered for donation of her lungs, liver, kidneys and pancreas. The heart was declined for unknown reasons.

\section{Differential Diagnosis}

Differential diagnosis of NS includes Treacher Collins Syndrome (TCS) which is characterized by anomalies of craniofacial development without preaxial limb malformations, Miller syndrome, and Richieri-Costa-Pereira syndrome [5]. Other mandibulofacial dysostoses such as type Toriello, type HederaToriello-Petty, type Bauru and type Verloes share similarities with NS in terms of facial and thumb anomalies [6].

\section{Treatment}

Recovery of her organs included liver, bilateral kidneys, pancreas and lungs. There were no internal deviations in anatomy with the exception of three renal arteries to the right kidney. The organs were appropriate size for her body mass. They were perfused, procured in standard protocol and offered to three different transplant centers. The pancreas was allocated for islets cell transplantation but it did not reach the standards required for successful transplantation as the number of viable islets was insufficient. The lungs were transplanted in another institution. The recipient of the lung transplant did well initially but she developed early rejection and serious respiratory infections in the first two weeks post transplantation. Information on the long-term outcome of the lung transplant recipient was declined by the transplant physicians at the other centre. The recipient of the liver and kidney grafts underwent standard transplant surgeries without any intra or perioperative complications. Immunosuppression for the liver transplant recipients included induction with solumedrol and Basiliximab with postoperative quick tapering of prednisone and maintenance on tacrolimus and Mycophenolate Mofetil (MMF). The renal transplant patients were induced with solumedrol and Anti-Thymoglobulin (ATG), postoperatively were given quick taper of prednisone, two doses of ATG and maintained on tacrolimus and MMF.

\section{Outcome and Follow-Up}

The liver was transplanted in a 60-year old man with alcoholic cirrhosis conditioning encephalopathy, esophageal varices, ascites and with a Model for End Stage Liver Disease 
(MELD) score of 23. The right kidney was transplanted in a 69-year old woman with end stage renal disease secondary to glomerulonephritis and on hemodialysis. The left kidney was transplanted in a 30-year old woman with previously failed living related kidney transplant for multicystic dysplastic kidneys and also on hemodialysis. The warm ischemia time for the liver, right and left kidneys were 62, 30 and 28 minutes respectively. The liver and renal function tests of the three recipients are summarized in Table 1 . All the recipients were discharged home with functioning grafts and alive at 12 months.

\section{Discussion}

NS is an extremely rare disorder described by Nager and de Reynier in 1948 [7]. As of 2012, ninety four cases of NS have been documented [8] with an incidence of 3:1,000,000 in Finland [5]. Rarity of this syndrome, in addition to various external and internal organ anomalies might be the reason for the lack of reports of NS patients becoming solid organ donors. Patients affected by NS can present with a very wide spectrum of anatomical abnormalities. Central nervous system anomalies include microcephaly, aqueductal stenosis with resultant hydrocephalous and polymicrogyria [4]. NS has not been associated with the development of cerebrovascular arterial aneurysms. Nevertheless, the multi-organ donor that we have described was affected by multiple arterial aneurysms that conditioned her demise due to subarachnoid haemorrhage. Most often these patients are of normal intelligence and stature. The developmental delays are attributed to hearing, feeding and respiratory difficulties in early age [9]. Hence these patients might present with reduced stature, speech difficulties and mild mental retardation. Tetralogy of Fallot, atrial, muscular ventricular and subaortic ventricular septal defects, ventricular hypertrophy, cardiomegaly, aortic stenosis and pulmonary bronchial stenosis are the most common cardiovascular conditions associated with NS $[5,10,11]$. Gastroschisis and Hirschsprung's disease are the most common gastrointestinal anomalies described in NS patients. The genitourinary system can also be affected. Aplastic or dystopic kidneys, duplicated ureters, external genital hypoplasia and vesicoureteral reflux may be responsible for dilation of renal pelvis and calyces with interruption of parenchymal architecture resulting in chronic renal insufficiency [12]. Other internal organ anomalies are uterus duplex and atrophic thymus [13]. The patient presented here had characteristic clinical findings of NS. She had atypical appearance, short in stature, had micrognathia, high nasal bridge, internal rotation of the forearm because of loss of extension, had developmental delay and was diagnosed with a fragile chromosome 3 . Review of literature has resulted in one another case report published in a child of NS with 3p14 common fragile site [14].

To our knowledge, there has been no report of organ procurement from NS patients and hence lack of understanding how these organs function when transplanted. This case has shown that NS patients can be potential organ donors and the organs procured functioned well.

The community of transplant surgeons should to be aware

Table 1: Trends in serum transaminases, INR and bilirubin for the recipient of the liver graft and serum creatinine and estimated glomerular filtration rates for the two recipients of renal grafts.

\begin{tabular}{|c|c|c|c|c|c|c|c|c|c|}
\hline $\begin{array}{c}\text { Organ } \\
\text { Function } \\
\text { Variables }\end{array}$ & Units & $\begin{array}{c}\text { Pre } \\
\text { Transplant }\end{array}$ & $\begin{array}{c}\text { Post } \\
\text { Transplant } \\
\text { Day } 1\end{array}$ & $\begin{array}{c}\text { Post } \\
\text { Transplant } \\
\text { Day } 3\end{array}$ & $\begin{array}{c}\text { Post } \\
\text { Transplant } \\
\text { Day } 5\end{array}$ & $\begin{array}{c}\text { Post } \\
\text { Transplant } \\
\text { Day } 7\end{array}$ & $\begin{array}{c}\text { Post } \\
\text { transplant } \\
\text { Days } 14\end{array}$ & $\begin{array}{l}6 \text { Months } \\
\text { Post } \\
\text { Transplant }\end{array}$ & $\begin{array}{c}12 \\
\text { Months } \\
\text { Post } \\
\text { Trans- } \\
\text { plant }\end{array}$ \\
\hline $\begin{array}{c}\text { Total } \\
\text { Bilirubin }\end{array}$ & (umol/L) & 82 & 120 & 85 & 65 & 26 & 11 & 8 & 7 \\
\hline $\begin{array}{c}\text { Direct } \\
\text { Bilirubin }\end{array}$ & (umol/L) & 16 & NA & 57.3 & 40 & 11.5 & 3.4 & NA & NA \\
\hline AST & $(\mathrm{U} / \mathrm{L})$ & 37 & 243 & 87 & 63 & 29 & 28 & 30 & 16 \\
\hline ALT & $(\mathrm{U} / \mathrm{L})$ & 16 & 159 & 52 & 63 & 31 & 20 & 48 & 8 \\
\hline ALP & $(\mathrm{U} / \mathrm{L})$ & 75 & 63 & 52 & 94 & 184 & 84 & 262 & 153 \\
\hline INR & & 2.2 & 1.3 & 1.4 & NA & 0.9 & 1 & 1 & 0.9 \\
\hline $\begin{array}{c}\text { Right } \\
\text { Kidney } \mathrm{Cr}\end{array}$ & (umol/L) & 574 & 485 & 377 & 226 & 138 & 114 & 117 & 109 \\
\hline $\begin{array}{c}\text { Right } \\
\text { Kidney } \\
\text { eGFR }\end{array}$ & $\left(\mathrm{ml} / \mathrm{min} / 1.73 \mathrm{~m}^{2}\right)$ & 7 & 8 & 11 & 20 & 35 & 44 & 42 & 43 \\
\hline $\begin{array}{l}\text { Left Kidney } \\
\text { Cr }\end{array}$ & (umol/L) & 492 & 402 & 168 & 125 & 124 & 121 & 134 & 127 \\
\hline $\begin{array}{l}\text { Left Kidney } \\
\text { eGFR }\end{array}$ & $\left(\mathrm{ml} / \mathrm{min} / 1.73 \mathrm{~m}^{2}\right)$ & 10 & 12 & 33 & 47 & 47 & 48 & 41 & 43 \\
\hline
\end{tabular}

Cr: Creatinine; umol/L: micromoles/Liter; AST: aspartate aminotransferase; ALT: alanine aminotransferase; AP: Alkaline phosphatase; U/L: units/ liter; INR: International Normalized Ratio; eGFR: estimated Glomerular Filtration Rate; ml/min/1.73m²: milliliters/minute/meter-square; NA: Notapplicable. 
of the possibility of internal organ anomalies that might be encountered during organ-retrieval and that these patients might necessitate additional preoperative work-up to determine the presence of anomalies affecting the heart, lungs and kidneys.

\section{Learning Points/Take Home Messages}

- Nager Syndrome, most often presenting sporadically is a rare disorder associated with pre-axial acrofacial dysostosis.

- Clinical findings are downslanting palpebral fissures, malar/mandibular hypoplasia, high nasal bridge, micrognathia, external ear anomalies, cleft palate, upper limb deformities and axial skeletal anomalies.

- Internal organ anomalies are noted with cardiopulmonary, gastrointestinal, genitourinary and central nervous system.

- Transplant team needs to be aware of the possibility of internal organ anatomical and functional anomalies for that might prompt further preoperative testing/imaging.

- The solid organs of kidneys and liver functioned well in our case with resolution of primary pathology in the recipients.

\section{References}

1. Vargervik K. Mandibular malformations: growth characteristics and management in hemifacial microsomia and Nager syndrome. Acta Odontol Scand. 1998 ; 56(6): 331-338.

2. Sulik KK, Smiley SJ, Turvey TA, Speight HS, Johnston MC. Pathogenesis of cleft palate in Treacher Collins, Nager, and Miller syndromes. Cleft Palate J. 1989 ; 26(3): 209-216; discussion 216.

3. Lin JL. Nager syndrome: a case report. Pediatr Neonatol. 2012; 53(2): 147-150. doi: 10.1016/j.pedneo.2012.01.014.

4. McDonald MT, Gorski JL. Nager acrofacial dysostosis. J Med Genet. 1993; 30(9): 779-782.
5. Nur BG, Bernier FP, Oztekin O, Kardelen F, Kalay S, Parboosingh JS, et al. Possible autosomal recessive inheritance in an infant with acrofacial dysostosis similar to Nager syndrome. Am J Med Genet A. 2013; 161(9): 2311-2315. doi: 10.1002/ajmg.a.36051.

6. Czeschik JC, Voigt C, Alanay Y, Albrecht B, Avci S, Fitzpatrick D, et al. Clinical and mutation data in 12 patients with the clinical diagnosis of Nager syndrome. Hum Genet. 2013; 132(8): 885-898. doi: 10.1007/ s00439-013-1295-2.

7. Meyerson MD, Jensen KM, Meyers JM, Hall BD. Nager acrofacial dysostosis: early intervention and long-term planning. Cleft Palate J. 1977; 14(1): 35-40.

8. Schlieve T, Almusa M, Miloro M, Kolokythas A. Temporomandibular joint replacement for ankylosis correction in Nager syndrome: case report and review of the literature. J Oral Maxillofac Surg. 2012; 70(3): 616-625. doi: 10.1016/j.joms.2011.02.053.

9. Paladini D, Tartaglione A, Lamberti A, Lapadula C, Martinelli P. Prenatal ultrasound diagnosis of Nager syndrome. Ultrasound Obstet Gynecol. 2003; 21(2): 195-197.

10.Waggoner DJ, Ciske DJ, Dowton SB, Watson MS. Deletion of 1q in a patient with acrofacial dysostosis. Am J Med Genet. 1999; 82(4): 301304.

11. Burton BK, Nadler HL. Nager acrofacial dysostosis: report of a case. J Pediatr. 1977; 91(1): 84-86.

12. Kavadia S, Kaklamanos EG, Antoniades K, Lafazanis V, Tramma D. Nager syndrome (preaxial acrofacial dysostosis): a case report. Oral Surg Oral Med Oral Pathol Oral Radiol Endod. 2004 Jun;97(6):732738.

13. Danziger I, Brodsky L, Perry R, Nusbaum S, Bernat J, Robinson L. Nager's acrofacial dysostosis. Case report and review of the literature. Int J Pediatr Otorhinolaryngol. 1990;20(3): 225-240.

14.Scapoli L, Martinelli M, Pezzetti F, Carahelli E, Carinci F, Cenzi R. Spontaneous expression of FRA3P in a patient with Nager syndrome. Am J Med Genet A. 2003; 118A(3): 293-295. 